\title{
Trinta anos, visibilidade e ensaios clínicos
}

\author{
Thirty years, visibility and clinical trials
}

Avenida Bandeirantes, 3.900

CEP 14049-900 - Ribeirão Preto/SP

Fone: (16) 3602-2803

E-mail: andrade@fmrp.usp.br

Recebido

28/11/2007

Aceito com modificacōes

$21 / 12 / 2007$
Estamos no final de 2007 e a Revista Brasileira de Ginecologia e Obstetrícia (RBGO) inicia o seu $30^{\circ}$ ano de circulação. Fundada por Jean Claude Nahoum, a seguir, foi editada pela professora Clarice do Amaral Ferreira, até 1993, e pelo professor Sérgio Pereira da Cunha, até 1997. Não é o momento de historiar a trajetória da publicação, mas é importante lembrarmos as dificuldades para divulgação das informações até há poucos anos e comparar com os dias atuais, quando dispomos das facilidades oferecidas pela divulgação na rede. Estas facilidades fazem com que, no momento, a meta para todos os periódicos seja a de aumentar a visibilidade das informações publicadas e, neste quesito, com a ajuda da tecnologia de informações, o acesso dos leitores tem sido bastante facilitado. Já em 1995, se antecipava que as revistas da área da saúde editadas em papel sofreriam modificações importantes para não deixarem de ser lidas ${ }^{1}$ e, de fato, não há atualmente nenhum periódico impresso relevante que não tenha a correspondente versão eletrônica, o que é facilmente verificável.

Desde 2001, a RBGO está representada na base de dados da Scientific Electronic Library Online (SciELO), na qual estão disponíveis os arquivos dos trabalhos publicados desde o volume 20 (1998). A base de dados SciELO é uma biblioteca eletrônica que abrange uma coleção selecionada de periódicos científicos ibero-americanos. É o resultado de uma parceria entre a Fundação de Amparo à Pesquisa do Estado de São Paulo (Fapesp) e o Centro Latino-Americano e do Caribe de Informação em Ciências da Saúde (Bireme), iniciada em 1997. Desde 2002, conta também com o apoio do Conselho Nacional de Desenvolvimento Científico e Tecnológico $(\mathrm{CNPq})^{2}$. Atualmente, o banco de dados da SciELO Brasil conta com 173 revistas brasileiras de todas as áreas do conhecimento e cerca de 60 da área da saúde.

Professor Titular do Departamento de Ginecologia e Obstetrícia da Faculdade de Medicina de Ribeirão Preto da Universidade de São Paulo - FMRP/USP - Ribeirão Preto (SP), Brasil; Editor Científico da Revista Brasileira de Ginecologia e Obstetrícia (RBGO). 
A repercussão de um trabalho pode ser medida pelo número de citações que ele recebe em outros artigos ou, secundariamente, pelo número de leitores ou de acessos nas bases de dados. Entre as estatísticas disponíveis no sistema SciELO, está o número de acessos para cada periódico indexado. Esse indicador fornece a quantidade de acessos efetuados pelos usuários da SciELO à página principal da revista, ao índice ou sumário, aos artigos e a outras seções da publicação ${ }^{2}$. A RBGO é o periódico especializado da área clínico-cirúrgica, cujos trabalhos foram os mais acessados em 2007. Em 2002 (primeiro ano em que este dado é disponível para a RBGO), o número de acessos à página inicial da revista foi 12.809 e 8.399 aos artigos publicados na forma completa (html e PDF). Estes números foram de 25.967 e 57.866, respectivamente, em 2003; 28.952 e 220.251, em 2004; 41.133 e 503.366, em 2005; 43.855 e 831.773, em 2006 e 66.597 e 1.603.543, em 2007. De 2006 para 2007 ocorreu, portanto, duplicação do número de leituras dos trabalhos completos publicados pela RBGO. O aumento do número de acessos foi verificado também em todas as revistas disponíveis na base de dados SciELO, mostrando maior familiaridade dos leitores com as revistas on-line, ao mesmo tempo que sugere a importância crescente da literatura especializada para os médicos brasileiros.

Pode se especular que parte substancial destes leitores seja composta por pesquisadores ligados às universidades e pós-graduandos, mas, provavelmente (devido ao grande número de acessos), a maior parte deve ser constituída de ginecologistas, obstetras ou colegas de outras especialidades à procura de atualização. Deste modo, as revistas cumprem um papel pouco valorizado e mesmo negligenciado, quando se aborda a questão da visibilidade, que é a divulgação de conhecimentos relevantes para a prática clínica.

Outro indicador interessante é o número de acessos a cada artigo. Esse indicador mostra quais os artigos de cada revista foram mais procurados. A análise desse indicador pode indicar aos editores quais os assuntos e artigos que despertaram mais interesse dos leitores da revista e, portanto, é útil para orientar a política editorial e a seleção de trabalhos para publicação. Oferece também aos autores a medida de popularidade de seus artigos.

Neste fascículo, destacamos ainda o agradecimento aos revisores externos ao Conselho Editorial. Foram, neste ano, 70 colegas da especialidade, de outras áreas ou de outras carreiras da área da saúde que colaboraram para a melhora do nível da nossa revista. Para os autores, podemos informar que esperamos implementar, durante este ano, o processamento on-line de manuscritos no sistema recentemente disponibilizado pela equipe da SciELO. Estamos também avançando para sermos incluídos em bases de dados internacionais, estando previstas decisões dos gestores destas organizações ainda para o início deste ano.

\section{Estudos clínicos}

De acordo com uma deliberação recente para o Brasil, mas que já vem sendo aplicada em vários outros países, os periódicos referenciados nas bases de dados Bireme e SciELO deverão solicitar o registro prévio dos ensaios clínicos e respectivo número de identificação como condição para análise e aceitação dos trabalhos derivados destes estudos. Essa decisão segue a orientação da Plataforma Internacional para Registros de Ensaios Clínicos (ICTRP), da Organização Mundial da Saúde (OMS), do International Committee of Medical Journal Editors (ICMJE) e de conclusões dos debates ocorridos no workshop ICTRP: Stategies to promote adherence to the International Clinical Trials Registry Platform in Latin America \& the Caribbean, realizado durante o $8^{\circ}$ Congresso Brasileiro de Saúde Coletiva e o $11^{\circ}$ Congresso Mundial de Saúde Pública, em 2006.

Desta forma, somente serão aceitos os trabalhos de pesquisa clínica que tenham um número de identificação fornecido por um dos registradores - número este que deve estar citado no trabalho, na página de rosto (ver adiante o roteiro para o registro). Estas providências fazem parte de um conjunto de iniciativas que visam basicamente eliminar ou reduzir o viés que resulta na publicação apenas dos ensaios com resultados positivos ou significantes, que são considerados mais interessantes para divulgação, pelos pesquisadores ${ }^{3}$. Esta preocupação se explica pelo fato de que este tipo de estudo tem se mostrado fundamental para evolução dos conhecimentos. Além disto, estes estudos randomizados e controlados de intervenção e as revisões sistemáticas neles baseadas são atualmente consideradas como de mais alto nível de evidência para delineamento de novas condutas clínicas ${ }^{4}$.

Para finalidade deste registro, uma pesquisa clínica (clinical trial) é definida como qualquer estudo que inclua, de forma prospectiva, seres humanos como sujeito de uma ou mais intervenções relacionadas à saúde, tendo como objetivo a verificação e avaliação dos efeitos destas intervenções. As intervenções, por sua vez, compreendem não só drogas como terapia celular ou com outros produtos biológicos, procedimentos cirúrgicos, uso de métodos de imagem, tratamentos comportamentais, preventivos etc. Os estudos de fase I, de toxicidade ou farmacocinética estão excluídos desta definiçãos. 
A necessidade de registro destes estudos é mencionada na nova versão das Instruções para Autores da RBGO, disponível nos fascículos impressos e na versão eletrônica acessada a partir dos sites da Federação Brasileira das Associações de Ginecologia e Obstetrícia (Febrasgo) e SciELO. Informações sobre as justificativas e o histórico destes registros podem ser lidos em www.who.int/ictrp/en/. Para registro dos estudos, podem ser empregados os registradores primários, dos quais o que é relacionado à própria OMS, o ICTRP, pode ser acessado nos seguintes endereços: www.who.int/ictrp/network/primary registers/isrctn/en/index.html, http://isrctn.org/ e www.controlledtrials.com/isrctn/submission, sendo o último destinado ao registro dos estudos.

Está também incluído no portal da OMS, sendo considerado como registrador primário: www.clinicaltrials. gov/, www.clinicaltrials.gov/ct2/invest e http://prsinfo.clinicaltrials.gov/ do National Institute of Health (NIH). Outros registradores podem ser empregados, inclusive o latino-americano (www.latinrec.org/index.htm). Uma relação das bases de dados para registro pode ser obtida no endereço da ICTRP. Para submissão de pedido de registro, o estudo deve ter sido previamente aprovado por uma Comissão de Ética em Pesquisa, mas o registro deve anteceder a inclusão do primeiro paciente.

\section{Referências}

1. LaPorte RE, Marler E, Akazawa S, Sauer F, Gamboa C, Shenton C, et al. The death of biomedical journals. BM. 1995;310(6991):1387-90.

2. Goldenberg S, Castro RCF, Azevedo FRM. Interpretação dos dados estatísticos da SciELO (Scientific Eletronic Library Online). Acta Cir Bras. 2007;22(1):1-7.

3. Dickersin K, Min Yl. Publication bias: the problem that won't go away. Ann N Y Acad Sci. 1993;703:135-46.

4. Lins ES. Registro de ensaios clínicos: declaração do Comitê Internacional de Editores de Revistas Médicas. Rev Assoc Med Bras. 2004;50(4):352-3.

5. DeAngelis C, Drazen JM, Frizelle FA, Haug C, Hoey J, Horton R, et al. Clinical trial registration: a statement from the International Committee of Medical Journal Editors. Lancet. 2004;364 (9438):911-2. 